\title{
Severe Acute Respiratory Syndrome Coronavirus-2 Antibody Responses in Hospitalized Patients with Coronavirus Disease 2019 in Daegu, Korea
}

\section{Yu Kyung Kim}

Kyungpook National University School of Medicine https://orcid.org/0000-0002-4699-8502

\section{Dohsik Minn}

Seegene medical foundation

\section{Eun-Hyung Yoo}

Daegu Catholic University Hospital: Daegu Catholic University Medical Center

\section{Mikyoung Park}

Yeungnam University School of Medicine and College of Medicine

\section{Jae Hee Lee}

Keimyung University Dongsan Hospital: Keimyung University Dongsan Medical Center

Jung-Sook Ha

Keimyung University College of Medicine: Keimyung University School of Medicine

Ji Yeon Ham

Kyungpook National University School of Medicine

Soon Hee Chang

Daegu Fatima Hospital

\section{Hyun Chul Lee}

Kyungpook National University School of Medicine

\section{Jang Soo Suh}

Kyungpook National University School of Medicine

\section{Chang-Ho Jeon}

Daegu Catholic University Hospital: Daegu Catholic University Medical Center

\section{Do-Hoon Kim}

Keimyung University College of Medicine: Keimyung University School of Medicine

\section{Sunggyun Park}

Keimyung University College of Medicine: Keimyung University School of Medicine

\section{Nan Young Lee}

Kyungpook National University School of Medicine

\section{Kyung Eun Song}

Kyungpook National University School of Medicine

\section{Soohyun Kim}

Seegene medical foundation

\section{Tae Yeob Kim}

Seegene medical foundation

\section{Sang-Gyung Kim ( $\sim$ sgkim@cu.ac.kr)}

Daegu Catholic University Hospital https://orcid.org/0000-0001-6596-4175 


\section{Research article}

Keywords: COVID-19, SARS-CoV-2 PCR, ELISA, Antibody Response

Posted Date: November 24th, 2020

DOI: https://doi.org/10.21203/rs.3.rs-107728/v1

License: (c) (i) This work is licensed under a Creative Commons Attribution 4.0 International License. Read Full License

Version of Record: A version of this preprint was published at Clinical Laboratory on January 1st, 2021. See the published version at https://doi.org/10.7754/Clin.Lab.2021.210305. 


\section{Abstract}

Background: Coronavirus disease 2019 (COVID-19) caused by severe acute respiratory syndrome coronavirus-2 (SARSCoV-2) started to spread in Daegu from the end of February 2020. IgG and IgM antibodies against SARS-CoV-2 were measured in hospitalized patients with COVID-19 with moderate to severe symptoms to improve the understanding of antibody responses.

Methods: We enrolled 312 patients with COVID-19 admitted to seven hospitals located in Daegu. Using serum (or plasma) samples from patients with polymerase chain reaction (PCR)-confirmed SARS-CoV-2 infections, both IgG and IgM antibodies were measured using commercial enzyme-linked immunosorbent assay (R-FIND COVID-19 ELISA, SG medical, Seoul, Korea).

Results: The median value from the initial diagnosis by confirming SARS-CoV-2 PCR to the sampling date was 24 days (day -1 to 88 ). The total positive rate of $\lg$ was $93.9 \%$ and the positive IgM rate was $39.4 \%$, without considering the elapsed period after diagnosis. Positive IgG and IgM rates were highest at $100.0 \%$ and $59.0 \%$ in 3 weeks (15-21 days), respectively. IgG showed a high positive rate of $79.3 \%$ even within 7 days after the initial diagnosis of the disease and maintained a positive rate of $97.8 \%$ until after 8 weeks.

Conclusions: Among hospitalized patients with COVID-19, IgG was detected from the beginning of the diagnosis and persisted for an extended time period.

\section{Background}

The outbreak of coronavirus disease 2019 (COVID-19) caused by severe acute respiratory syndrome coronavirus-2 (SARS-CoV-2) that started in December 2019 was declared as a pandemic by the World Health Organization in March 2020. ${ }^{1}$ COVID-19 exhibits various clinical symptoms, from asymptomatic, and mild symptoms to fatal progression. Although it often appears as a respiratory symptom, it is also commonly associated with nonspecific symptoms, such as diarrhea and headaches. Therefore, it cannot be diagnosed based on symptoms only, the polymerase chain reaction (PCR) test to detect the RNA of SARS-CoV-2 is the widely used diagnostic method of choice. ${ }^{2}$

Recently, several immunoassays have been developed for SARS-CoV-2 antibodies, such as enzyme-linked immunosorbent assay (ELISA), chemiluminescence enzyme immunoassays (CLIA), fluorescence immunoassays (FIA), and the lateral flow immunoassays (LFIA), and many researchers investigated the immune response of patients with COVID-19. ${ }^{3-10}$ However, a clear understanding of the antibody response of patients with COVID-19 is still lacking. ${ }^{2,11-12}$ To improve understanding of antibody responses, IgG and IgM antibodies were measured among 312 patients with COVID-19 admitted to seven hospitals from the explosive spreading period in Daegu.

\section{Methods}

\section{Subjects selection}

We enrolled 312 patients hospitalized for SARS-CoV-2 from seven hospitals located in Daegu from March to May 2020 (Table 1). All patients were initially diagnosed by confirming SARS-CoV-2 infection via the PCR method. For the PCR test, one hospital used the Powerchek 2019-nCoV Real-time PCR kit (KogeneBiotech, Seoul, Korea), and the remaining six hospitals used the Allplex 2019-nCoV assay (Seegene, Seoul, Korea). Hospitalization was determined according to the severity scoring system, ${ }^{13}$ and majority of patients had moderate to severe symptoms (2-4 criteria; Table 2 ). 
Table 1

Patient distribution in each institution

\begin{tabular}{|c|c|c|c|c|c|c|c|c|c|c|c|c|c|}
\hline \multirow[t]{2}{*}{ Institution } & \multirow[t]{2}{*}{$\mathbf{N}$} & \multicolumn{3}{|l|}{ Age } & \multicolumn{2}{|c|}{ Male } & \multicolumn{3}{|c|}{ Days after diagnosis } & \multicolumn{2}{|c|}{$\begin{array}{l}\text { Positive rate } \\
\text { of IgG }\end{array}$} & \multicolumn{2}{|c|}{$\begin{array}{l}\text { Positive } \\
\text { rate of IgM }\end{array}$} \\
\hline & & Median & Min & Max & $\mathbf{N}$ & $\%$ & Median & Min & Max & $\mathbf{N}$ & $\%$ & $\mathbf{N}$ & $\%$ \\
\hline $\begin{array}{l}\text { Hospital } \\
\text { A }\end{array}$ & 73 & 67 & 25 & 90 & 44 & 60.3 & 24 & -1 & 76 & 68 & 93.2 & 38 & 52.1 \\
\hline $\begin{array}{l}\text { Hospital } \\
\text { B }\end{array}$ & 60 & 72 & 27 & 89 & 26 & 43.3 & 26 & 0 & 45 & 59 & 98.3 & 26 & 43.3 \\
\hline $\begin{array}{l}\text { Hospital } \\
\text { C }\end{array}$ & 49 & 49 & 7 & 86 & 11 & 22.4 & 4 & 1 & 88 & 43 & 87.8 & 14 & 28.6 \\
\hline $\begin{array}{l}\text { Hospital } \\
\text { D }\end{array}$ & 44 & 70 & 38 & 90 & 28 & 63.6 & 11 & -1 & 50 & 40 & 90.9 & 18 & 40.9 \\
\hline $\begin{array}{l}\text { Hospital } \\
\text { E }\end{array}$ & 34 & 64 & 22 & 97 & 19 & 55.9 & 34 & 2 & 71 & 32 & 94.1 & 17 & 50.0 \\
\hline $\begin{array}{l}\text { Hospital } \\
\text { F }\end{array}$ & 32 & 57 & 14 & 95 & 12 & 27.3 & 44 & 2 & 70 & 31 & 96.9 & 7 & 21.9 \\
\hline $\begin{array}{l}\text { Hospital } \\
\text { G }\end{array}$ & 20 & 72 & 25 & 90 & 5 & 14.7 & 39 & 10 & 71 & 20 & 100.0 & 3 & 15.0 \\
\hline Total & 312 & 67 & 7 & 97 & 145 & 40.1 & 24 & -1 & 88 & 293 & 93.9 & 123 & 39.4 \\
\hline control & 50 & 58 & 30 & 84 & 25 & 50.0 & - & - & - & 0 & 0.0 & 0 & 0.0 \\
\hline
\end{tabular}

Table 2

Classification according to clinical symptoms and treatment criteria

\begin{tabular}{|lll|}
\hline Classification & Symptoms and treatment & Recommendation \\
\hline 1) Asymptomatic to mild & No symptoms or & Discharge or \\
& $\mathrm{BT}<37.5^{\circ} \mathrm{C}$ & community treatment center \\
\hline 2) Moderate & $\mathrm{BT} \geq 37.5^{\circ} \mathrm{C}$ and & General ward \\
\hline no oxygen treatment required & \\
\hline 4) Critical & Oxygen treatment requiring a nasal or venturi mask & General ward \\
\hline & High flow oxygen treatment or & Intensive care unit \\
\hline
\end{tabular}

Fifty normal healthy participants without clinical symptoms of infection and without contact with SARS-CoV-2-positive patients were selected as negative controls (male/female, 1:1; mean age, 57 years).

In order to investigate the positive rate, one sample was selected for each patient from follow-up serum or plasma stored at $-70{ }^{\circ} \mathrm{C}$ for a total of 312 patients.

To determine the positive rate according to the period elapsed after the initial diagnosis, a total of 305 samples were finally selected, excluding patients who did not know the date of the first diagnosis among 312 samples.

To determine whether the antibody response differed according to the disease severity, nine deceased patients with classification 4 (the deceased group; male/female, 2:1; mean age, 72.7 years) and nine patients with classification 2 
(the moderate group; male/female, 2:1; mean age, 73.4 year) matched by sex and age of the deceased group were selected. A total of 78 samples (42 samples from the deceased group and 36 samples from the moderate group) collected between 15 and 35 days after the initial diagnosis were used.

To investigate the trend in the positive rate of RT-PCR and antibody tests, we collected SARS-CoV-2 PCR results from 246 patients who underwent RT-PCR within 3 days before and after blood collection.

\section{SARS-CoV-2 antibody ELISA}

Serum (or plasma) IgM and IgG antibodies against SARS-CoV-2 were measured using newly developed ELISA kits (RFIND COVID-19 ELISA, SG medical, Seoul, Korea), according to the manufacturer's instructions. According to the manufacturer's data, the sensitivity of R-FIND COVID-19 IgG ELISA is $94.12 \%$, and specificity is $98.12 \%$. The sensitivity and specificity of IgM ELISA are $84.21 \%$ and $100 \%$, respectively. Both ELISA uses the recombinant nucleocapsid protein (NP) of SARS-CoV-2. Samples were diluted 1:101 in the assay buffer and incubated for 45 min in microwells coated with NP protein, followed by washing protocols and incubation cycles to detect antibodies present in patient samples using rabbit anti-human IgG as a secondary antibody. The enzyme used in the ELISA test was horseradish peroxidase, and the substrate was 3,3',5,5'-Tetramethylbenzidine. Optical density (OD) was measured at $450 \mathrm{~nm}$, and the signal $\mathrm{OD} /$ cut-off OD value (S/C value) for each sample was calculated by dividing the sample signal OD by the positive cutoff OD using the positive cut-off OD for each batch.

\section{Statistical analysis}

Independent $t$-test after Levene's test was used to compare the $\mathrm{S} / \mathrm{C}$ value according to the elapsed period. Chi-square or Fisher's exact test, according to the expected value, was used to compare the positive IgG and IgM rates between the deceased and moderated groups. In order to compare the S/C value of these two groups, the Mann-Whitney U-test was used. All statistical analyses were performed using SPSS software ver. 22.0 (IBM, Armonk, NY, USA).

\section{Results}

\section{Patient distribution and positive rate of antibodies in the entire 312 samples}

The average age of 312 patients in seven institutions was 67 (7-97) years, and the male-to-female ratio was 4:6. The median value from the initial diagnosis to the sampling date is 24 days, and samples from the day before diagnosis to 88 days after diagnosis were collected. By institution, the positive lgG rate was at least $87.8 \%$, the maximum value was $100 \%$, the positive IgM rate was at least $15.0 \%$, and the maximum was $52.1 \%$. Of 312 samples from 312 patients, 293 samples (93.9\%) were positive for IgG and 123 (39.4\%) were positive for IgM. The IgG and IgM of 50 control samples were all negative (Table 1).

\section{Antibody responses according to the elapsed period after the initial diagnosis}

The positive IgG rate was $79.3 \%$ at 1 week after the disease diagnosis and reached $100 \%$ at 3 weeks. Even after 8 weeks, a positive rate of $97.8 \%$ was maintained. The IgM was $25.9 \%$ in week 1 after the initial diagnosis and reached its peak of $59.0 \%$ in week 3 . After that, the positive rate continued to decrease, and after 8 weeks, it dropped to $17.8 \%$ (Fig. 1. A). The S/C value and the positive rate of both IgG and IgM generally showed similar increasing patterns, respectively. However, after 8 weeks, the positive IgG rate was maintained at $97.8 \%$, whereas the S/C value was significantly lower than the previous week $(P<0.05)$ (Fig. 1. A, and B). 


\section{Antibody responses according to the disease severity}

The positive IgG rate was higher in the deceased group than that in the moderated group, and the positive IgM rate was lower in the deceased group, but no statistical significance (Fig. 2. A). The S/C value of IgG and IgM also showed the same pattern as the positive rate. Moreover, especially in the S/C value of IgG was significantly higher in the deceased group $(P<0.05)$ (Fig. 2. B).

\section{Trend of the positive rate of RT-PCR and antibody tests}

The positive PCR rate was $47.2 \%$ a week after the disease diagnosis and decreased to $4.5 \%$ after 8 weeks. Ig G continued to increase after diagnosis and maintained a positive rate of $97.7 \%$ after 8 weeks, and IgM increased to a maximum at 3 weeks and decreased to $13.6 \%$ after 8 weeks (Fig. 3).

\section{Discussion}

In this study of 312 patients with COVID-19 with moderate to severe symptoms, the total positive IgG rate was $93.9 \%$ and the positive IgM rate was $39.4 \%$, without considering the elapsed period after the diagnosis. Both IgG and IgM reached the highest positive rate in 3 weeks (15-21 days), $100.0 \%$ and $59.0 \%$, respectively. IgG showed a high positive rate of $79.3 \%$ even within 7 days after the initial disease diagnosis and maintained a positive rate of $97.8 \%$ until after 8 weeks. Similar to the authors' study, Kohmer et al. reported that the positive rate of IgG was 93-100\% on the 10-18th day after the initial PCR diagnosis of 33 hospitalized patients, ${ }^{3}$ and Long et al. also reported that the positive rate reached $100 \%$ within 19 days. ${ }^{4}$ Conversely, the positive rate of IgM continued to decrease after reaching the highest value at 3 weeks, and after 8 weeks, the positive rate was $17.8 \%$. In this study, all eight patients (17.8\%) with IgM positive results after 8 weeks were positive for IgM and IgG simultaneously, including one patient with the longest elapsed time after diagnosis at 88 days. The authors compared the positive and S/C value of IgG and IgM according to the disease severity. No significant difference was observed, except that the S/C value of IgG was significantly higher in the deceased group than in the moderate group. Long et al. ${ }^{4}$ reported that the $\mathrm{IgG}$ of critical patients was significantly higher than that of mild patients, as shown in this study. Several studies demonstrated that the positive IgG rate was somewhat constant; however, the positive rate of IgM was relatively different. ${ }^{11}$ Since the elapsed period of each study participant was different, there seemed to be a difference in the positive IgM rate, which was more affected by the period after the initial diagnosis. In other studies, samples were used within approximately 1 month after the initial diagnosis, ${ }^{4-7,11}$ whereas $39.1 \%$ (122 samples) in this study were sampled 5 weeks (29-88 days) after the diagnosis. This may be one of the reasons why the lgM positive rate in this study is relatively low compared to other studies. Moreover, differences in sensitivity and specificity according to various immunoassay methods such as ELISA, CLIA, FIA, and LFIA were observed. Even in the same method, the assay was performed depends on the antigen, such as NP,

spike sugar protein (S), and spike sugar protein receptor-binding domain, designed to respond to the antibody. $8,11-12$ The authors used an ELISA method to detect antibodies against NP, which is reported to be less sensitive than antibodies against $\mathrm{S}$ or antibodies targeting both $\mathrm{S}$ and NP. ${ }^{12}$ As previously described, results of the antibody test are reported differently according to the difference between the antibody test method, target antigen, or research group. Therefore, the clinical accuracy and analytical performance of the test result should be verified through various researches on the antibody response in patients with COVID-19.

The SARS-CoV-2 PCR test is the most necessary confirmation test to diagnose COVID-19. ${ }^{2}$ However, if deciding the disease onset remains difficult, repeated trials of PCR tests are inevitable. Moreover, PCR test results vary depending on the sample type, collection method, gene selected for detection, or interpretation criteria. ${ }^{2}$ If COVID-19 is clinically suspected, but PCR test results are unclear, antibody tests could be used as a supplement. Notably, in IgG, as it 
increases from the initial diagnosis of COVID-19 and remains even after an extended period, it will be useful to determine infected persons not identified by PCR. However, to use a specific antibody test as a diagnostic tool, a series of studies that prove the accuracy and sensitivity of the test should be continuously performed for both healthy individuals and patients.

This study was conducted on patients with an explosive increase in Daegu and included patients diagnosed with a fullscale investigation regardless of symptoms. In particular, since a significant number of patients who were transferred due to worsening disease after being diagnosed in nursing hospitals were included in this study, the symptom onset of COVID-19 could not be accurately investigated. Because the authors determined the duration of the disease based on RT-PCR results, there was a limitation that the exact disease course of COVID-19 was not reflected.

\section{Conclusion}

We found that the total positive rate of IgG was $93.9 \%$ and the positive $\operatorname{lgM}$ rate was $39.4 \%$, without considering the elapsed period after diagnosis. Both IgG and IgM reached the highest positive rate in 3 weeks (15-21 days), IgG showed a high positive rate of $79.3 \%$ even within 7 days after the initial diagnosis of the disease and maintained a positive rate of $97.8 \%$ until after 8 weeks. In conclusion, this study found that in hospitalized patients with moderate to severe symptoms, IgG was found at the disease onset and persisted for an extended period.

\section{Abbreviations}

COVID-19

Coronavirus disease 2019

SARS-CoV-2

severe acute respiratory syndrome coronavirus-2

PCR

polymerase chain reaction

ELISA

enzyme-linked immunosorbent assay

CLIA

chemiluminescence enzyme immunoassays

FIA

fluorescence immunoassays

LFIA

lateral flow immunoassays

OD

Optical density

$\mathrm{S} / \mathrm{C}$ value

signal OD/cut-off OD value

\section{Declarations}

\section{Ethics approval and consent to participate}

The present study protocol was reviewed and approved by the Daegu Joint Institutional Review Board (approval No. 2020-09-006). Since samples remaining after routine blood tests were used, the Daegu Joint Institutional Review Board approved the study without the informed consent. 


\section{Consent for publication}

Not applicable

\section{Availability of data and materials}

All data generated or analysed during this study are included in this published article.

\section{Competing interests}

The authors declare that they have no competing interests

\section{Funding}

This work was supported by the Research Program of Medicity Daegu Council funded by Daegu Metropolitan City (fund code: COVID19_DM02).

\section{Author Contributions}

Conceptualization: Kim YK, Kim SG, Ha JS, Chang SH, Ham JY. Methodology: Kim YK, Minn D, Kim TY. Formal analysis: Minn D, Kim S, Kim YK. Data curation: Yoo EH, Park M, Park S, Lee HC, Lee NY. Investigation: Kim S, Lee JH, Kim DH. Supervision: Suh JS, Song KE, Jeon CH Writing - original draft preparation: Kim YK. Writing - review and editing: Kim YK, Kim SG. Approval of final manuscript: all authors.

\section{Acknowledgements}

Not applicable

\section{References}

1. Guan WJ, Ni ZY, Hu Y, Liang WH, Ou CQ, He JX, et al. Clinical Characteristics of Coronavirus Disease 2019 in China. China Medical Treatment Expert Group for Covid-19. N Engl J Med. 2020;382(18):1708-20.

2. Tang YW, Schmitz JE, Persing DH, Stratton CW. Laboratory Diagnosis of COVID-19: Current Issues and Challenges. J Clin Microbiol. 2020;58(6):e00512-20.

3. Kohmer N, Westhaus S, Rühl C, Ciesek S, Rabenau HF. Clinical performance of different SARS-CoV-2 IgG antibody tests. J Med Virol 2020.

4. Long QX, Liu BZ, Deng HJ, Wu GC, Deng K, Chen YK, et al. Antibody responses to SARS-CoV-2 in patients with COVID-19. Nat Med. 2020;26(6):845-48.

5. Guo L, Ren L, Yang S, Xiao M, Chang D, Yang F, et al. Profiling Early Humoral Response to Diagnose Novel Coronavirus Disease (COVID-19). Clin Infect Dis 2020:ciaa310.

6. Zhao J, Yuan Q, Wang H, Liu W, Liao X, Su Y, et al. Antibody responses to SARS-CoV-2 in patients of novel coronavirus disease 2019. Clin Infect Dis 2020:ciaa344.

7. Okba NMA, Müller MA, Li W, Wang C, GeurtsvanKessel CH, Corman VM, et al. Severe Acute Respiratory Syndrome Coronavirus 2-Specific Antibody Responses in Coronavirus Disease Patients. Emerg Infect Dis. 2020;26(7):147888.

8. Liu W, Liu L, Kou G, Zheng Y, Ding Y, Ni W, et al. Evaluation of Nucleocapsid and Spike Protein-Based EnzymeLinked Immunosorbent Assays for Detecting Antibodies against SARS-CoV-2. J Clin Microbiol. 2020;58(6):e0046120. 
9. To KK, Tsang OT, Leung WS, Tam AR, Wu TC, Lung DC, et al. Temporal profiles of viral load in posterior oropharyngeal saliva samples and serum antibody responses during infection by SARS-CoV-2: an observational cohort study. Lancet Infect Dis. 2020;20(5):565-74.

10. Amanat F, Stadlbauer D, Strohmeier S, Nguyen THO, Chromikova V, McMahon M, et al. A serological assay to detect SARS-CoV-2 seroconversion in humans. Nat Med. 2020;26(7):1033-6.

11. Kontou PI, Braliou GG, Dimou NL, Nikolopoulos G, Bagos PG. Antibody tests in detecting SARS-CoV-2 infection: A meta-analysis. Diagnostics. 2020;10(5):319.

12. Theel ES, Slev P, Wheeler S, Couturier MR, Wong SJ, Kadkhoda K. The Role of Antibody Testing for SARS-CoV-2: Is There One? J Clin Microbiol 2020:JCM.00797 - 20.

13. Kim SW, Lee KS, Kim K, Lee JJ, Kim JY, Daegu Medical Association. A brief telephone severity scoring system and therapeutic living centers solved acute hospital-bed shortage during the COVID-19 outbreak in Daegu, Korea. J Korean Med Sci. 2020;35(15):e152.

\section{Figures}


(A)

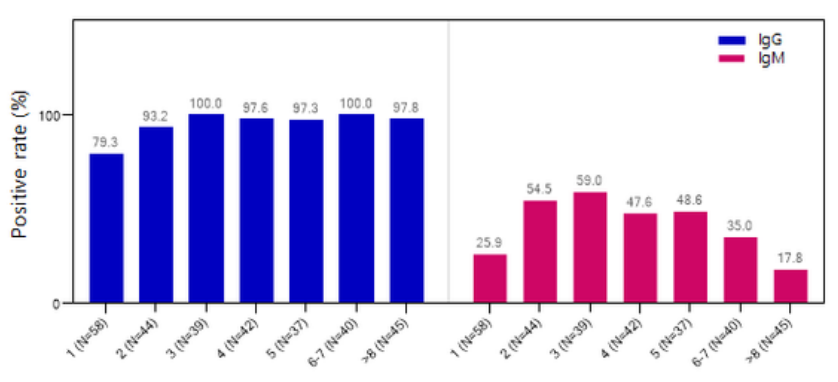

(B)

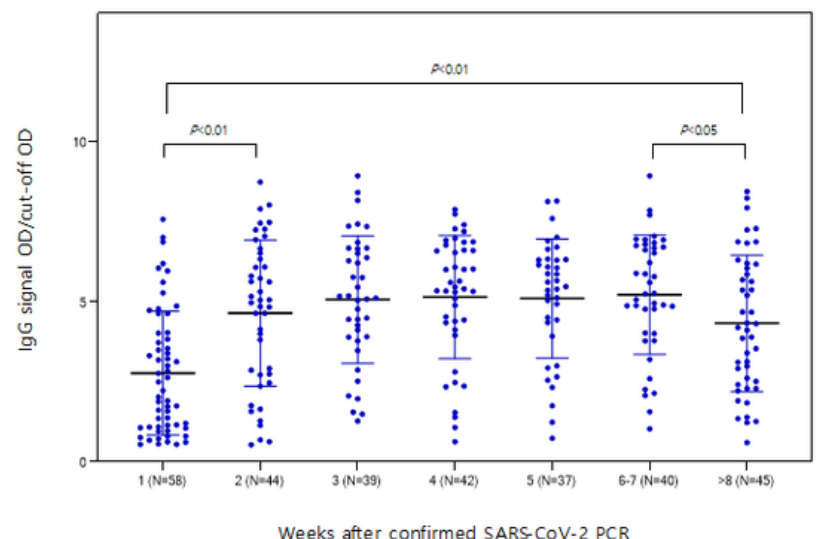

(C)

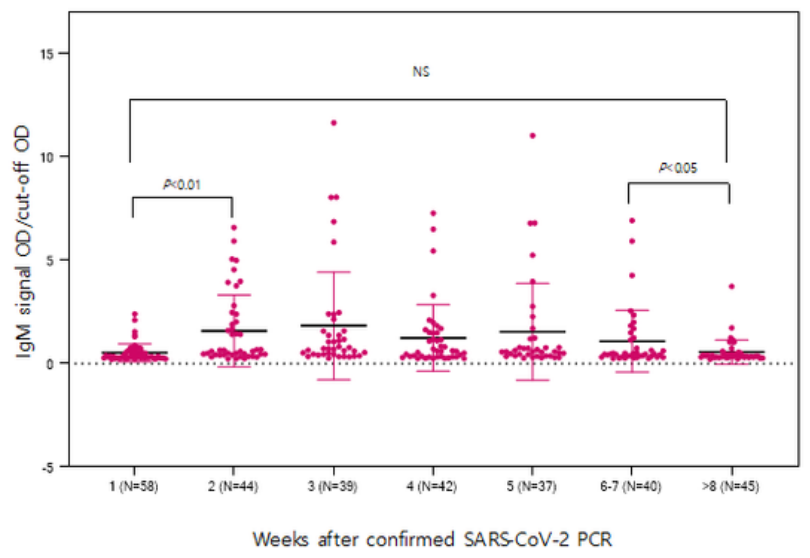

Figure 1

Antibody responses according to the elapsed period after a confirmed SARS-CoV-2 PCR (A), Positive rates of IgG and IgM, (B) and (C), Antibody signal OD/cut-off OD value (S/C value) in 305 samples from 305 patients. The lines of (B) and (C) show means (black line) and standard deviations (colored error bar). P-values were determined using an independent t-test. 
(A)

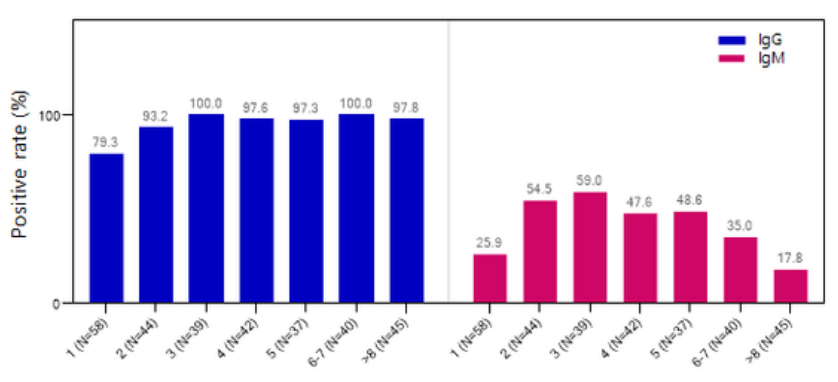

(B)

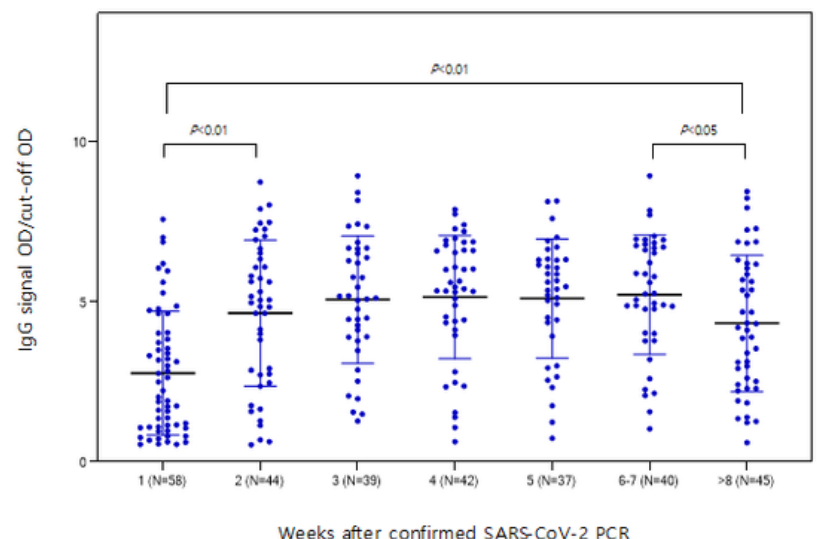

(C)

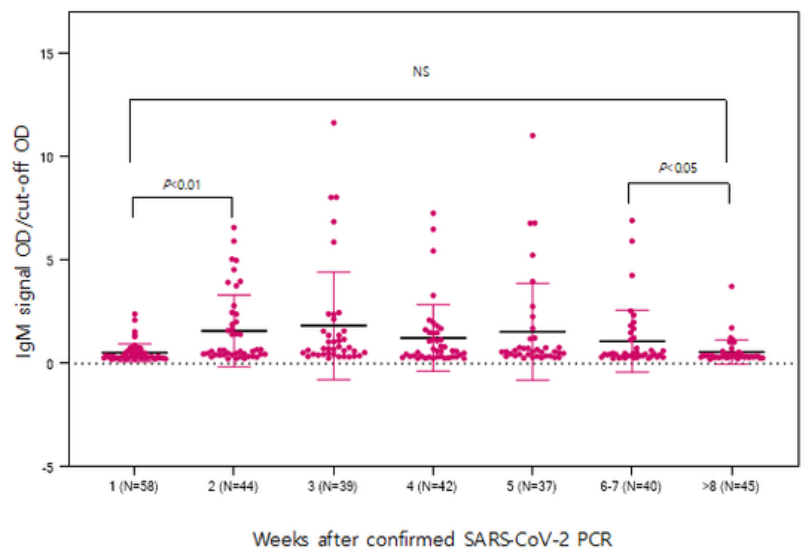

Figure 1

Antibody responses according to the elapsed period after a confirmed SARS-CoV-2 PCR (A), Positive rates of IgG and IgM, (B) and (C), Antibody signal OD/cut-off OD value (S/C value) in 305 samples from 305 patients. The lines of (B) and (C) show means (black line) and standard deviations (colored error bar). P-values were determined using an independent t-test. 
(A)

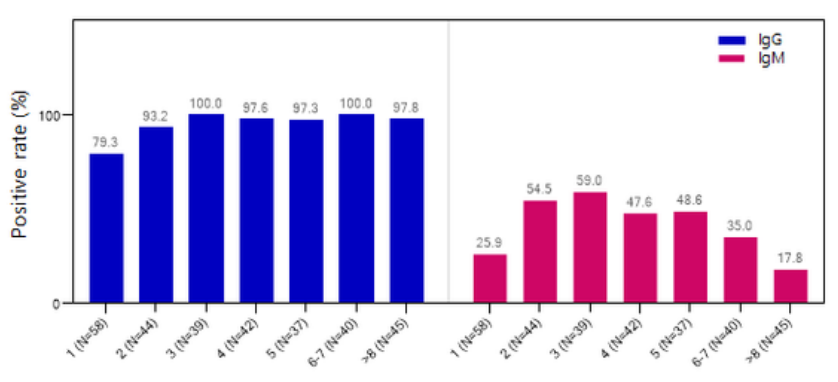

(B)

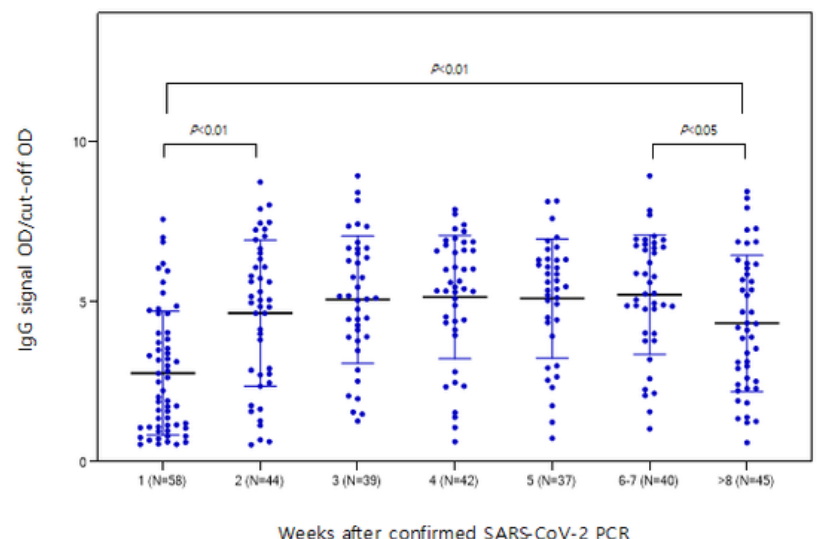

(C)

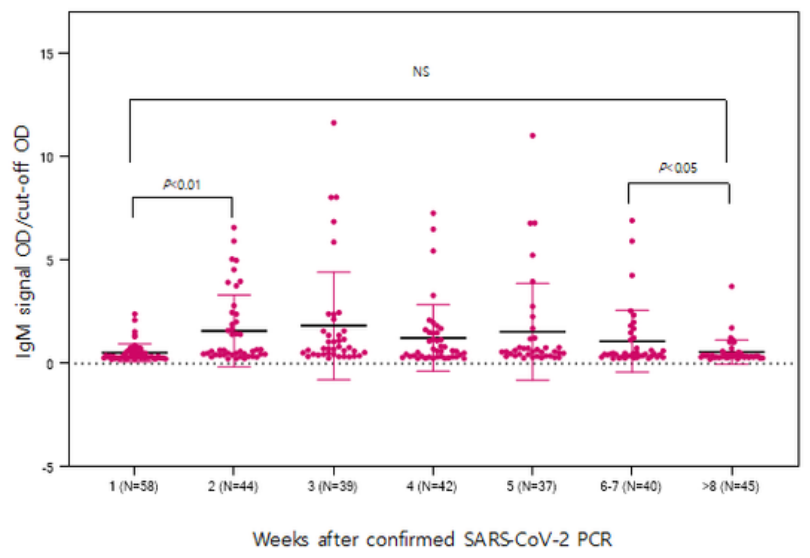

Figure 1

Antibody responses according to the elapsed period after a confirmed SARS-CoV-2 PCR (A), Positive rates of IgG and IgM, (B) and (C), Antibody signal OD/cut-off OD value (S/C value) in 305 samples from 305 patients. The lines of (B) and (C) show means (black line) and standard deviations (colored error bar). P-values were determined using an independent t-test. 
(A)

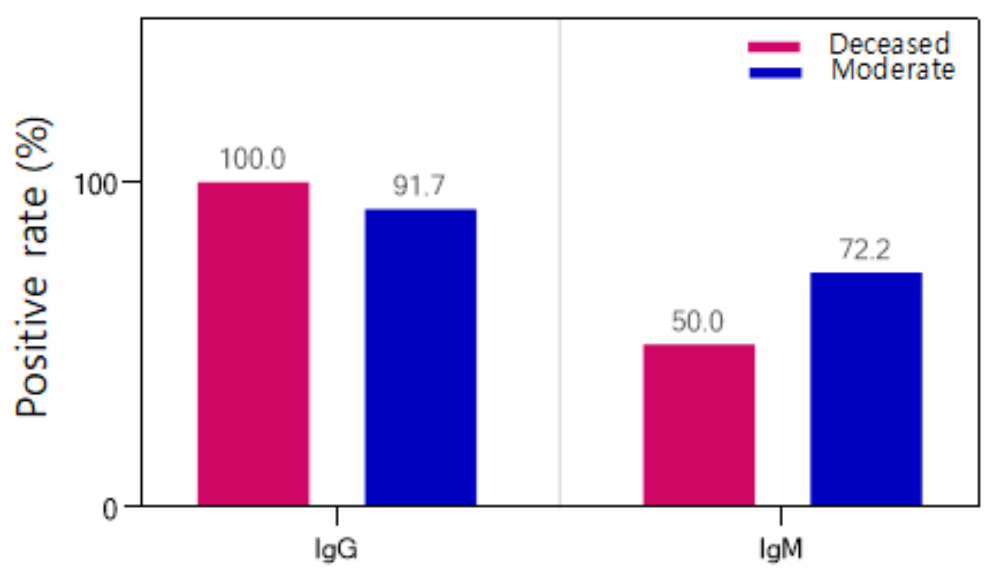

(B)

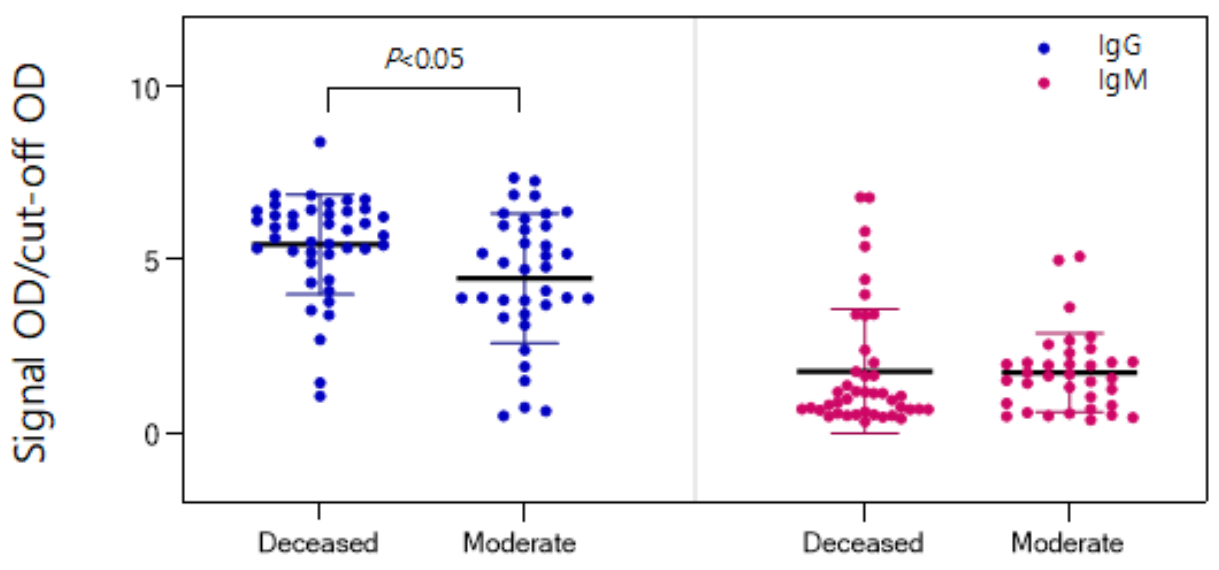

Figure 2

Antibody responses according to the disease severity (A) Positive rates of IgG and IgM, (B) Antibody signal OD/cut-off $O D$ value ( $\mathrm{S} / \mathrm{C}$ value) in 78 samples (42 samples of nine patients in the deceased group, 36 samples of nine patients in the moderate group) collected between 15 and 35 days after a confirmed SARS-CoV-2 PCR. The lines of (B) show means (black line) and standard deviations (colored error bar). P-values were determined with Mann-Whitney U-test. 
(A)

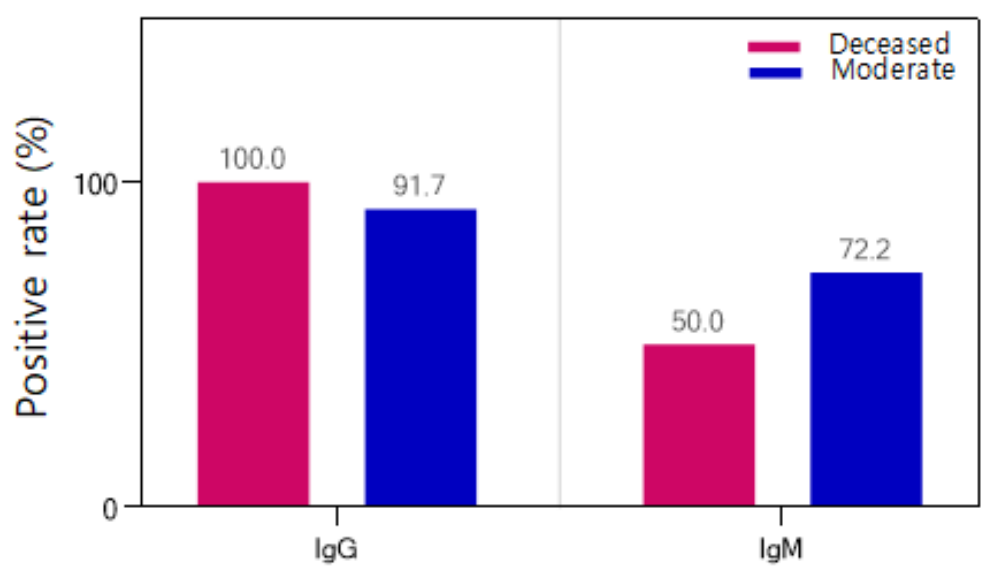

(B)

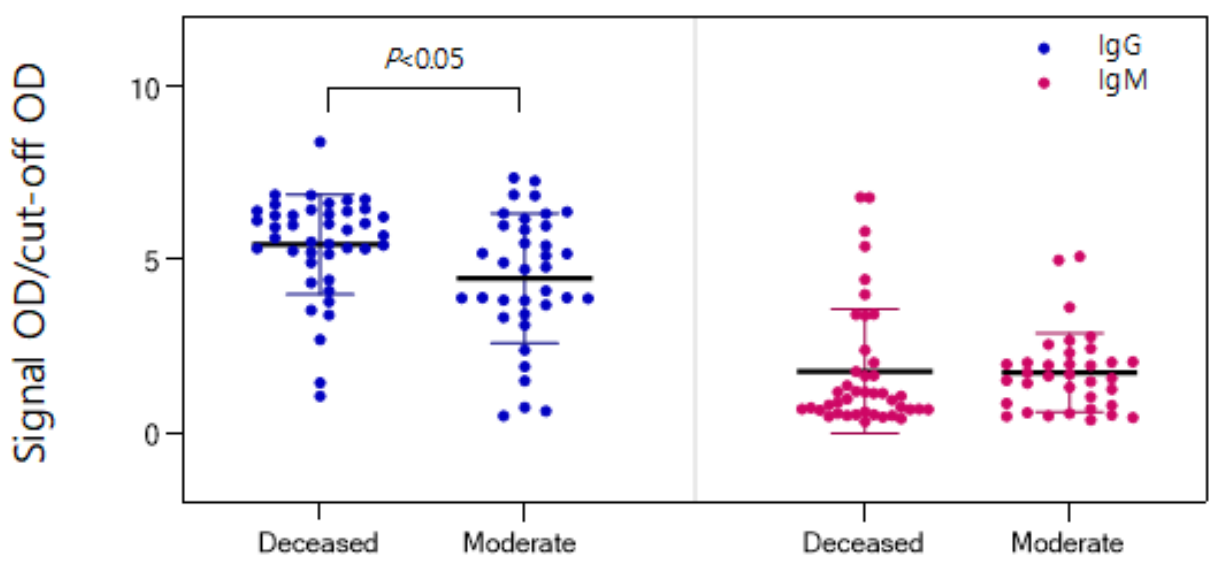

Figure 2

Antibody responses according to the disease severity (A) Positive rates of IgG and IgM, (B) Antibody signal OD/cut-off $O D$ value ( $\mathrm{S} / \mathrm{C}$ value) in 78 samples (42 samples of nine patients in the deceased group, 36 samples of nine patients in the moderate group) collected between 15 and 35 days after a confirmed SARS-CoV-2 PCR. The lines of (B) show means (black line) and standard deviations (colored error bar). P-values were determined with Mann-Whitney U-test. 
(A)

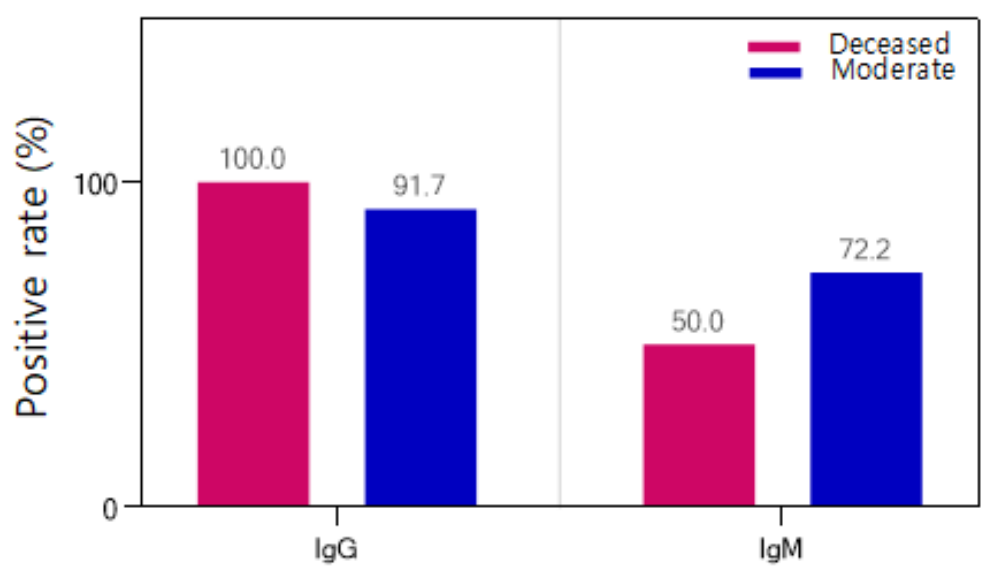

(B)

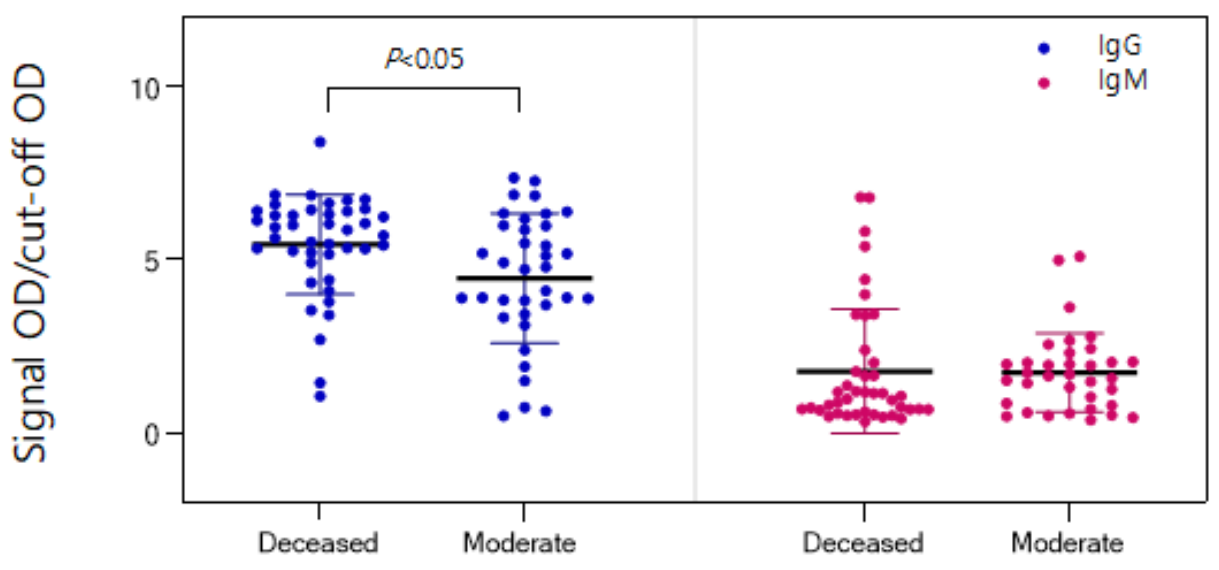

Figure 2

Antibody responses according to the disease severity (A) Positive rates of IgG and IgM, (B) Antibody signal OD/cut-off $O D$ value ( $\mathrm{S} / \mathrm{C}$ value) in 78 samples (42 samples of nine patients in the deceased group, 36 samples of nine patients in the moderate group) collected between 15 and 35 days after a confirmed SARS-CoV-2 PCR. The lines of (B) show means (black line) and standard deviations (colored error bar). P-values were determined with Mann-Whitney U-test. 


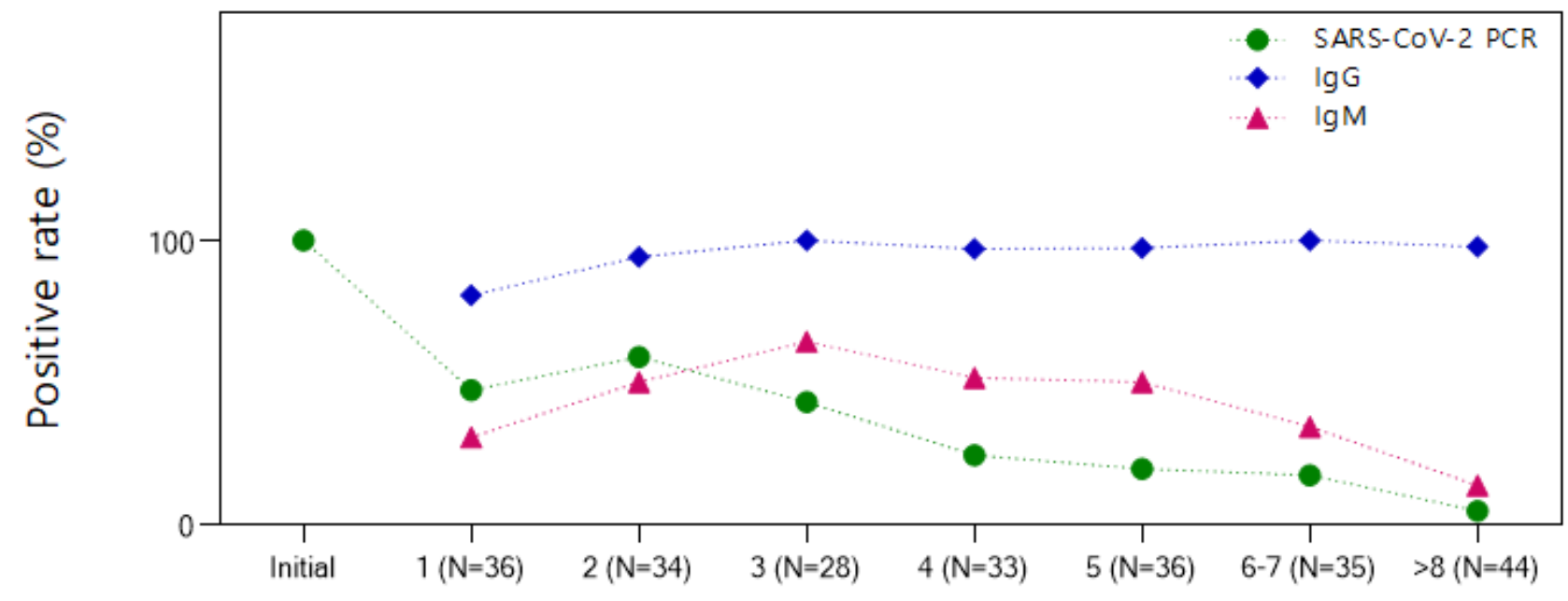

Weeks after confirmed SARS-CoV-2 PCR

Figure 3

The positive rate of PCR, IgG, and IgM according to the elapsed period after confirmed SARS-CoV-2 PCR

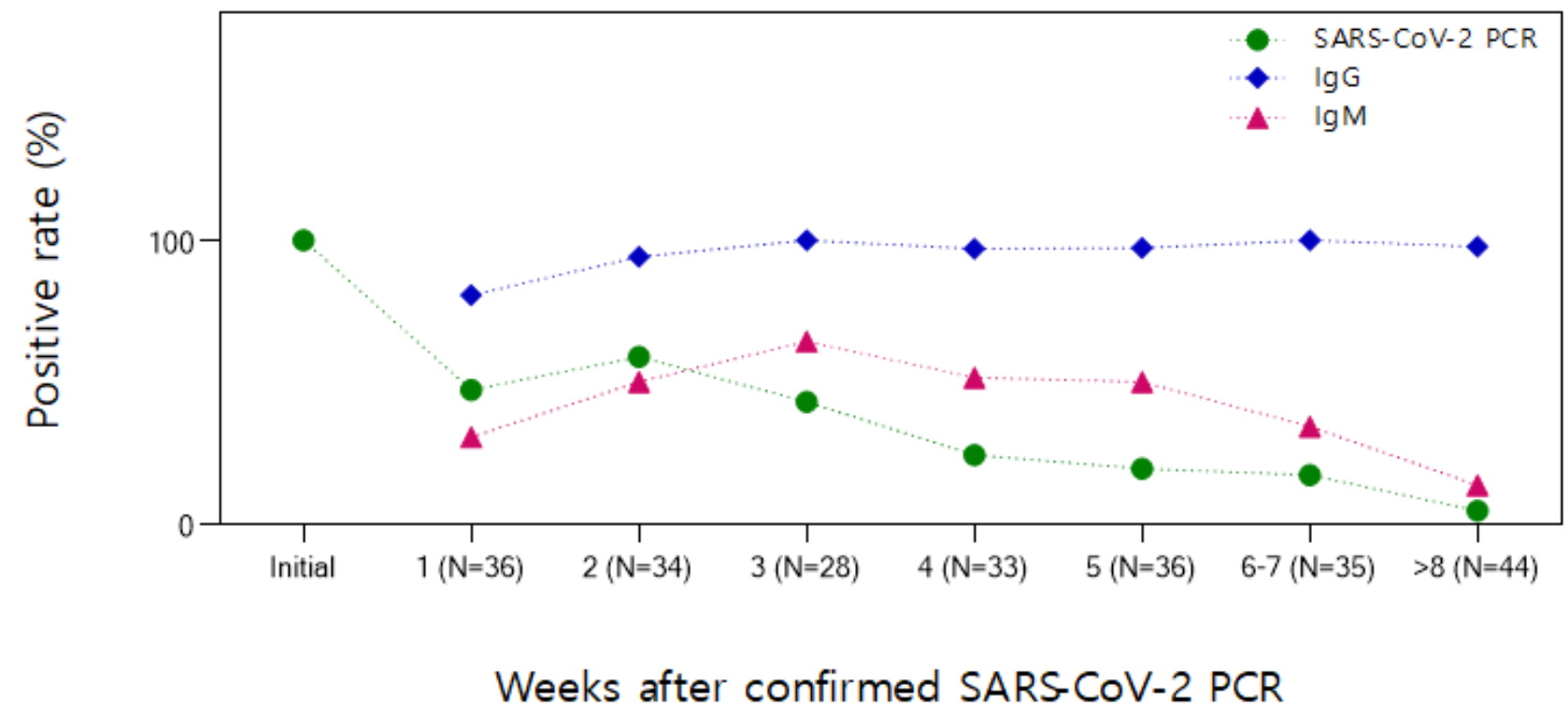

Figure 3

The positive rate of PCR, IgG, and IgM according to the elapsed period after confirmed SARS-CoV-2 PCR 


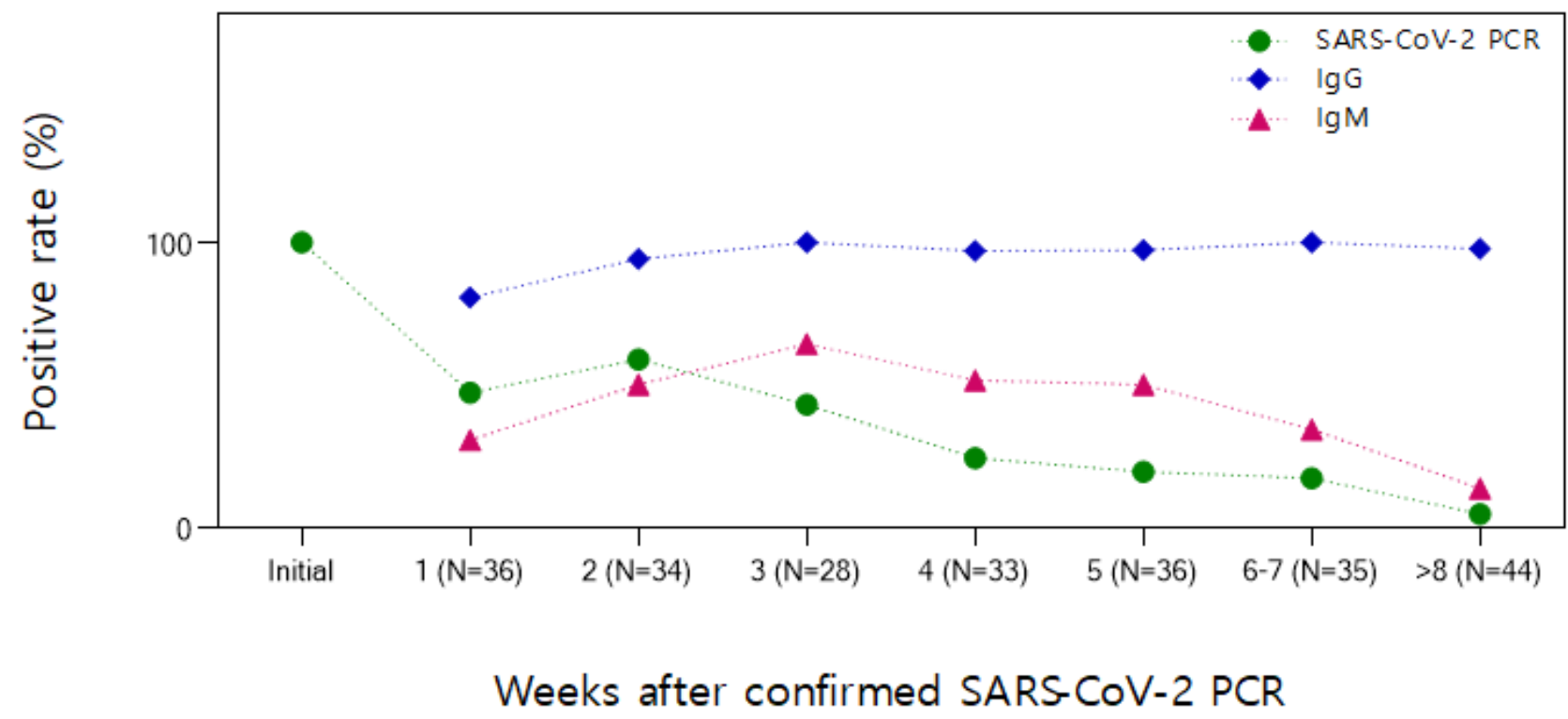

Figure 3

The positive rate of PCR, IgG, and IgM according to the elapsed period after confirmed SARS-CoV-2 PCR 